\title{
Mõtteid seoses \\ John Hattie ja Gregory Yatesi raamatuga „Nähtav õppimine ja teadus sellest, kuidas me õpime“"
}

\author{
Eve Kikas ${ }^{\mathrm{a}}$ \\ ${ }^{a}$ Tallinna Ülikooli loodus- ja terviseteaduste instituut
}

\begin{abstract}
Hattie, J., \& Yates, G. (2018). Nähtav õppimine ja teadus sellest, kuidas me oppime. Tallinn: Innove.
\end{abstract}

Austraalia Melbourne'i ülikooli haridusuuringute instituudi direktor John Hattie on kuulsaks saanud tänu õppimise efektiivsust hindavate metaanalüüside sünteesidele, mis on esitatud tema varasemas raamatus „Nähtav õppimine“. Nagu viitab pealkiri, käsitlevad need analüüsid pigem õppimise välist külge, kirjeldades näitajaid (edukuse indikaatoreid), mis on seotud efektiivsemate õpitulemustega (aluseks on võetud efekti suurus $d$ ja selle maagiline piir 0,40). Raamat on saavutanud suurt populaarsust eri maades, nt Austraalias (Eacott, 2017) ja Skandinaavia maades (Rømer, 2019). Ootuspäraselt on käsitlust ka kritiseeritud, seda nii teoreetilise (nt Rømer, 2019) kui ka statistilise ja uurimusliku kvaliteedi (Bergeron, 2017; Slavin, 2018) vajakajäämiste tõttu. Seevastu eesti keelde tõlgitud uuem raamat, mille Hattie on kirjutanud koos Lõuna-Austraalia ülikooli vanemlektori Greg Yatesiga, on mõeldud lugemiseks hoopis laiemale lugejaskonnale. Yatesi uurimistemaatika on pigem nähtavatagune - õppimise kognitiivsed ja motivatsioonilised alused (arutlemine, kognitiivne koormus, enesekontroll, enesejuhitud õppimine). Seega on tegu kahe suhteliselt erineva valdkonna ja uurijaga, mistõttu võib oodata, et nende koostööst sünnib huvitav ja kasulik teos.

Puutusin Hattie analüüside interpretatsiooniga kokku ühel konverentsil, mil mult pärast ettekannet küsiti: „Teie olete näidanud, et õpetus, mis toetub õpetaja tugevale kontrollile ja harjutamisele, pole üldiselt kõige efektiivsem, kuid Hattie analüüsid tõestavad just vastupidist. Kuidas seletate seda erinevust?" Mida ma vastasin, ma täpselt ei mäleta, kuid nõustusin raamatu ülevaadet kirjutama ka seetõttu, et saada täpsemalt teada, mida Hattie analüüsid ikkagi näitavad ja kas need on vastuolus meie uuringute tulemustega. Seega otsisin vastust küsimu- 
sele, kuidas autorid tõestavad, et kordamine-harjutamine on koolis põhilineoluline, ja kuidas raamat haakub suundumustega tänapäeva Eestis, kus rõhutatakse vajadust eemalduda drillist ja rakendada õppimise alusena vabamat probleemide lahendamist (nn muutunud, muutuv, uus õpikäsitus). Lugedes mõtlesin sellele, mis Eesti hariduses toimub, ja püüdsin mõista, kas ja kuivõrd täidab raamat lünki eestikeelses hariduskirjanduses.

Eeltoodule lisaks huvitas mind, kuidas on see õppimist ja õpetamist käsitlev ülipopulaarne raamat kirjutatud. Sihtrühmana on raamatu tagakaanel nimetatud nii õpetajaid, õpilasi kui ka lapsevanemaid, st suurt osa elanikkonnast. Seega oli kohane küsida, kuidas suudab raamat köita nii erinevat lugejaskonda. Olles raamatu läbi lugenud, võin kinnitada, et selles käsitletakse ilmselgelt selliseid küsimusi, mida on õpetajatel kasulik teada, kuid mis võivad huvi pakkuda ka lapsevanematele, et oma laste kooliprobleeme paremini mõista, ning ka õpilastele, et endast paremini aru saada. Raamat lõhub mitmeid Eestiski levinud müüte efektiivse õpetamise ja õppimise kohta. Samas pole see kogu tõde õppimisest, mistõttu oleks hea, kui raamatut loetaks kriitilise pilguga.

\section{Raamatus käsitletavad valdkonnad}

Esimene osa „Õppimine klassiruumis“ on pühendatud nähtava õppimisega seotud teemadele. Selles analüüsitakse, mida saaks õpetaja teha, et õpilased paremini õpiksid, arvestades mõistagi õppimise ja õpilaste eripäraga. Teos algab üldtuntud faktiga, et paljudele õpilastele kool ei meeldi, hiljem puudutatakse ka küsimusi, mis teeb õppimise raskeks ja kuidas paremini õppida. Mitu osa on seotud õpetaja tegevustega klassis: kui tähtis on ainealane kompetentsus (kas head teadmised takistavad või soodustavad õpetamist), miks on õpilase ja õpetaja head suhted olulised, miks on vaja olla empaatiline ja pöörata tähelepanu enda mitteverbaalsele käitumisele, kuidas avaldub õpetaja isiksus, kas õpetaja peaks olema õpilaste muutuste põhjustaja-aktiveerija või kõrvalseisja-suunaja? Arutletakse teemadel, mida tähendab tunniaja efektiivne kasutamine, miks tahavad mõned õpilased muutuda ning miks osa õpilasi muutub nähtamatuks (vrd Tove Janssoni „Nähtamatu laps“) ja kuidas seda protsessi vältida. Informatiivne on kiitmise ja tagasiside osa - rõhutatakse, et kiitmine ei vii edasi, vaid vaja on informeerivat tagasisidet, kusjuures jälgima peab seda, kuidas õppija tagasisidet vastu võtab. Autorid kirjeldavad ka vastuolu õpilaste ja õpetajate arusaamade vahel: õpetajad väidavad, et annavad tagasisidet, samas õpilased ei saa sellest aru. Õpilased vajavad ja tahavad konkreetseid, hästi mõistetavaid juhiseid, mis aitaksid edasi tegutseda, kuid õpetajate selgitused tunduvad neile ebapiisavad ja üldised. Eks Eesti kooliski on katsetatud alternatiivseid võimalusi, nt naerunägusid numbriliste hinnangute asemel, olgugi et 
need on sisult sama vähe informatiivsed. Kujundava hindamise sisuline sisseviimine koolidesse on kulgenud raskustega.

Teises osas käsitletakse õppimise aluseid. Erinevalt esimesest osast analüüsitakse ja kirjeldatakse siin rohkem õppija poolt, õppimisprotsessi. Kui aga teada, kuidas õpitakse, siis saab vastused ka küsimusele „Kuidas õpetada?“. Põgusalt kirjeldatakse ka õppimise põhitõdesid: õppimine nõuab aega, selle olulised suunajad on eelteadmised ja motivatsioon (tahe pingutada, aktiivsus), tähtis on õpitegevuste hajutamine ja kordamine. See info on esitatud punktide kaupa ning üpris populistlikult. Tegelikult vajaks iga punkt põhjalikumat selgitust. Edasi käsitletakse mälu ja mitteteadlikku õppimist. Pikemalt on juttu kognitiivsest koormusest, millele raamatu eri peatükkides korduvalt viidatakse. Kognitiivse koormusega põhjendatakse, miks algajaid ja edasijõudnuid tuleb õpetada erinevalt. Näiteks ei sobi probleemilahendamine kui õpiviis algajatele, sest sellega kaasneb suur kognitiivne koormus: enne peab olema midagi, millega mõtelda ja arutleda, alles siis saab hakata probleeme lahendama. See on kindlasti vajalik teadmine neile, kes on liigses vaimustuses avastus- ja probleemõppest. Siin toodud faktid viitavad selgelt vajadusele hoolikalt läbi mõelda, millal, kellega ja mis viisil neid meetodeid kasutada. Samas on ootamatu, et autorid ei arutle sügavamalt individualiseerimise, ülesannete jõukohasuse ja motivatsiooni üle. Põgus ülevaade antakse ka mälustrateegiatest, esitades mäluvõtteid, kuid ei põhjendata pikemalt, kuidas strateegiad töötavad. Õpistiilide temaatika ongi keeruline, informatiivsena rõhutatakse, et õpetada ei saa stiilide järgi, vaid tähtis on mõista, kuidas inimene õpib. Viimastes peatükkides käsitletakse tänapäeva probleeme: rööprähklemise ebaefektiivsust ning interneti, arvuti ja muusika osa õppimisel.

Ootasin, et kolmandas osas „Tunne ennast“ võetakse eespool esitatu kokku, kuid tegelikult tuuakse sisse uued teemad. Kirjutatu võimaldab õpetajal iseennast paremini mõista, samas annab see infot ka õpilaste kohta. Selle osa lugemist segab aga ebaühtlus terminite kasutamisel (nt üldine enesehinnang, akadeemiline enesehinnang, enesetõhusus, enesekindlus), raske on eri osi ja isegi lõike integreerida. Eri kohtade põhjal võib teha ka erinevaid järeldusi ning palju on üleüldistusi. Mõnel juhul viidatakse korrelatsioonanalüüsile, mille alusel ei saa tuvastada põhjusi ega mõju suunda, ammugi mitte teha mingeid järeldusi konkreetse inimese kohta. Näiteks väide „üldiselt on kõrge enesehinnangu tase kindlaks märgiks, et inimene tunneb elust rõõmu, saavutab eesmärke, tegeleb aktiivselt pingutust väärivate ettevõtmistega ning ka teised näevad teda eduka inimesena" (lk 204) pole kindlasti alati õige. Palju tähelepanu pööratakse mitteverbaalsele käitumisele. Lõpus käsitletakse sügavamalt ka kiiret ja aeglast mõtlemist (süsteeme 1 ja 2), millele on raamatu varasemates osades viidatud. Siin võiks soovitada juurde lugeda Daniel Kahnemani raa- 
matut „Kiire ja aeglane mõtlemine“ (2017). Viimases peatükis kirjeldatakse IKEA efekti (eesti keeles ka itk-efekt: ise tehtud kaunikene) ehk seda, et inimesed kalduvad paremaks, tähtsamaks või olulisemaks pidama neid asju, mille valmimisse on ise panustatud. See on hea teema, millega raamat lópetada, sest see võimaldab viidata õpilaste aktiivse osalemise tähtsusele mistahes (kooli) tegevustes. Samas seda osa kuigivõrd eelnevaga ei seostata. Puudust tundsin ka üldisest kokkuvõttest.

\section{Mis on huvitav: intrigeerivad väited}

Raamat on ilmselgelt kirjutatud intrigeerivalt, kuid ka nii, et kirjutatu sügavamaks mõistmiseks peaks lugeja kasutama aeglast mõtlemist (süsteemi 2). Hea näide on esimene peatükk „Miks õpilastele ei meeldi koolis õppida? Willinghami tees“. Nimelt tuuakse vastuseks, et inimese ajule ei meeldi üldjuhul mõtelda, et mõistus ei ole loodud mõtlemiseks. Loomulikult tekitab selline lihtne tees huvi edasi lugeda ja tõstatab küsimuse, kuidas on see võimalik - inimene on ju mõtleja (meenutagem August Rodini kuulsat skulptuuri „Mõtleja“), juba lastele meeldib lahendada probleeme (populaarsed nuputamisraamatud, pusled jm). Eestlastele võiks meenuda ka Hando Runneli luuletus „Mõtelda on mõnus", kus väidetakse hoopis, et rääkida on raskem. Probleemide lahendamist ja arutlemist tähtsustatakse (võrreldes päheõppimisega) uutes haridus- ja neuropsühholoogilistes käsitlustes. Siin aga kirjutatakse, et inimestele ei meeldigi mõtelda ... Kuidas seda teesi põhjendada? Aluseks võetakse mõtlemise definitsioon: „Mõtlemine tähendab erinevate vaatenurkade kaalumist. See tähendab impulsiivsuse mahasurumist ja vajaliku eelinformatsiooni puudumisel otsustamisest hoidumist. See tähendab tõendite ja uuringute kõrgemale tõstmist isiklikest arvamustest ja eelarvamustest. See tähendab avatust uutele ideedele“ (lk 9). Seega põhjendatakse mittemeeldimist teguritega, mis pole otseselt seotud mõtlemisega, rõhutades, et mõtlemine nõuab pingutamist, tekitab ebakindlust ja kartust ebaõnnestuda, mistõttu on lihtsam ja kindlam toetuda mälule ehk sellele, mida me juba teame. Lugemisel tekkis ka küsimus, kas seda, mida mõtlemise all mõeldakse, ikka (Eesti) koolis nõutakse. Kas koolis on vaja niisugusel tasemel arutlemist, avatust uutele ideedele? Pigem on siiani nimetatud kooliõppe probleemse küljena liigset toetumist mälule ja meeldejätmisele, mitte probleemide lahendamisele. Meil on levinud arvamus, et kool ei meeldi lastele just sellepärast, et infot peab pähe õppima. Kui väide, et mõtlemine ei meeldi, on õige, siis tuleks veelgi enam hoiduda aktiivõppest, õpilase aktiveerimisest! 
Intrigeerivad teesid on huvitavad, sest suunavad mõtlema, kuigi seda me ei taha teha. Kui siiski püüda täpsustada, kas ja mis (kooli)mõtlemises ei meeldi, siis jõuame ka tõele lähemale. Nagu tavaliselt, pole tõde lõppkokkuvõttes nii äärmuslik, ja sellele ka raamatus vihjatakse. Inimestele ei meeldi mõtelda, kui lüngad teadmistes on suured, kui teema ei paku huvi. Teiste sõnadega, meile ei meeldi tegeleda sellega, millest me aru ei saa. Tõepoolest tuleb tunnistada, et kui õpitav on keeruline, siis kaob lootus seda mõista ja lihtsam on materjali otseselt pähe õppida (ning hiljem unustada). Kui aga õpitav on uudne, kuid meie teadmiste tasemele kättesaadav, saavutatavate eesmärkidega, tekitab see nähtavasti ka huvi ja soovi pingutada - siis tunneme mõtlemisest mõnu. Kahjuks ei seostatud raamatus seda teemat piisavalt individualiseerimise ja eelteadmistega (hiljem neid küll käsitleti), huvi ja motivatsiooniga. Samuti tekkis soov kasutada Eesti õpetajatele ja haridustöötajatele tuntud konstrukti lähim arengutase või lähima arengu tsoon (Lev Võgotski teooriast; nt Võgotski, 1978). Kui need teemad sisse tuua, siis vast polegi nii lootusetu mõtlemisele toetuvat õppimist koolis juurutada? Samas on kooliõpe kohustuslik, õpitakse eri teemasid, palju tuleb ka pähe õppida, et selle õpitu baasil hakata lahendama keerukamaid probleeme ehk praktiseerida mõtlemist.

Ka teine peatükk „Kas head teadmised takistavad õpetamist?“ on intrigeeriv ja suunab arutlema. Väidetakse, et õpetajate (aine-)teadmiste sügavus on nõrgalt seotud sellega, kuidas õpilased õppetöös edenevad. Siit saaks kiire mõtlemise korral kohe järeldada, et õpetajatele ei olegi häid aineteadmisi vaja. See on muidugi vale loogiline järeldus, aga loogilise järeldamisega, st aeglase mõtlemisega, on paljud raskustes ... Seega võib pealiskaudsel lugemisel teha selle raamatu põhjal üpris valesid järeldusi. On selge, et head aineteadmised ei taga automaatselt oskust õpetada - see ongi eraldi oskus, mida õpetajaks õppides omandatakse. Aineteadmisi ei tohiks vaadelda õpetamisega seotud teadmistest ja oskustest eraldi. Jälle tundsin puudust lähima arengutaseme mõistest ja sellest, et peale aineteadmiste on vaja ka teadmisi psüühika toimimisest. Nii õpilase kui ka õpetaja omast.

Intrigeeriv ja eri arvamusi tekitav on kindlasti üheksas peatükk „Keerukate oskuste omandamine sotsiaalsete eeskujude ja eksplitsiitse õpetamise teel“. Mind huvitas vastandus õpetaja kui muutuste põhjustaja-aktiveerija vs. kõrvalseisja-suunaja. Autorid toovad näiteid selle kohta, et parimad õpetamistegevused on õpetajatel, kes on muutuste põhjustajad-aktiveerijad. Samas osutatakse terminoloogilisele segadusele (põhjustamisel ja aktiveerimisel, samuti kõrvalseismisel ja suunamisel on suur vahe!), mis selles valdkonnas valitseb, ja seda oli lugedes tõesti tunda, seega pole tegu tõlkeprobleemiga. Lisaks raskendab sisu mõistmist see, et tabelis 9.1 on tegevused-meetodid esitatud väga erineval üldistustasemel. Siin avaldub ka korrelatiivsete uuringute ja 
üldistatud efekti suurusega seotud probleemistik. Näiteks võib õpetaja kui aktiveerija tagasiside (suur mõju) olla tegelikult antud väga erineval tasemel. Veebipõhine õpe (õpetaja kui võimaldaja, väike mõju) sisaldab mitmesuguseid óppeviise, millest mõned võivad olla väga efektiivsed, isegi kui enamik seda ei ole.

Üheksandas peatükis kirjutatu tundus ka liialt mustvalge, mitme seisukohaga ei saa nõustuda. On selge, et lihtsalt vaatluse teel või iseseisvalt avastades keerukaid teadmisi-oskusi ei omandata. Samas näitavad uuringud kognitiivses psühholoogias, et teadmiste ülekanne ühelt inimeselt teisele on võimatu. Õppija saab uut infot näiteks suheldes, lugedes, kuulates ja vaadeldes, kuid ta peab selle uue info seostama olemasolevaga ja konstrueerima seeläbi lõpliku arusaama. Sellist õppimist ei saa samastada isikliku avastamise teel õppimisega ega sellele vastandada. Seega nõustun täielikult väitega „Arvamus, et kindlad teadmised tulenevad automaatselt isikliku avastamise läbi, on ennatlik ja ebaõige. ... On vähe alust väitmiseks, et isiklik avastamine soodustab iseenesest inimesel ka päriselt millegi omandamist“ (lk 75). Isikliku avastamise ja transmissiooni vahele jäävad aga paljud tegevused, mis eeldavad nii õpetaja kui ka õppija aktiivsust. Siin võiks viidata meie uurimistöödele (mille kohta konverentsil küsiti!), kus oleme näidanud, et kui õpetaja on kõrvalseisja rollis, annab õpilastele liigset vabadust ega struktureeri keskkonda ja tegevusi, siis ei toeta ta oma tegevusega üldiselt ei õpilaste teadmiste-oskuste ega motivatsiooni arengut. Samas võib isegi siin olla erandeid, nt klassides, kus õpivad huvilised õpilased ja kus on vähe käitumisprobleeme (Kikas, Peets, \& Hodges, 2014; Peets \& Kikas, 2017). Samuti võib õpilaste areng olla pärsitud klassides, kus õpetajad on liiga kontrollivad ja vähe empaatilised ning õpilased peavad materjali mehaaniliselt omandama (Pakarinen \& Kikas, 2019). Efektiivsed on õpetajad, kes kohandavad oma tegevusi klassi taseme järgi, annavad lahendada ülesandeid, arvestades õpilaste eelteadmisi-oskusi. Seega võiksid nad olla nii aktiveerijad kui ka suunajad.

\section{Mis on kasulik: küsimused, tekstikastid ja allikad peatükkide lõpus}

Küsimused järelemõtlemiseks iga osa lõpus suunavad teksti uuesti lugema ning teemade üle arutlema. Kuigi paljud on otsesed faktiküsimused, mille vastused on tekstis olemas, saaks neid (vajaduse korral laiendades) kasutada õppijatega arutlemiseks nii koolis kui ka ülikoolis. Seega saab tõesti lugeda peatükke ükshaaval ja nende üle arutleda. Samas, kuna teemad on vastuolulised, peavad õpetajad neid ise hästi teadma, sest muidu võivad nad aruteludes hätta jääda. Vastamine nõuab aeglase mõtlemise süsteemi rakendamist, kiirel ja pealis- 
kaudsel järeldamisel võidakse jääda endiste arvamuste juurde ja loetu võib lausa kinnistada varasemaid väärarusaamu, mida meil kõigil kindlasti on.

Tekstikastid „EELTOODU VALGUSES“ on huvitavad ja neid saab eraldi lugeda. Osa neist annab uut infot (laiendab, süvendab eelnevat), kuid eriti meeldisid mulle need kastid, kus oli toodud praktilisi suuniseid õpetajale. Kuna raamatuga soovitakse anda õpetajale juhiseid selle kohta, kuidas klassis õpilastega paremini toime tulla ja suunata neid efektiivsemalt õppima, siis võiks just selliseid praktilisi kirjeldusi olla rohkemgi. Osa tekstikaste sisaldab uut huvitavat teemakohast teavet, mitte ei muuda teoreetilist teavet rakenduslikumaks.

Allikad on hästi esitatud, varustatud kirjeldustega. Tekstis viited puuduvad, mistõttu on seda kergem lugeda. Huvi korral saab aga peatüki lõpust infot selle kohta, kust mida edasi otsida.

\section{Kokkuvõtteks}

Kui kokkuvõtlikult meenutada, mida peaksid õpetajad tegevuste planeerimisel arvestama, siis meenuvad esmalt konstruktid kognitiivne koormus, automatiseerumine ning kiire ja aeglane mótlemine. Kognitiivse koormusega ehk olukorraga, kus õppimine muutub nii keeruliseks, et õpilased ei suuda enam efektiivselt tegutseda, tuleb eelkõige arvestada aktiivõppemeetodeid rakendades. Samuti viitab see individualiseerimise olulisusele. Protsesside automatiseerumiseks vajalik kordamine-harjutamine on samuti temaatika, mida veel kord rõhutada, kuna kohati tundub, et selle vajadust hakatakse alahindama. Kiirete otsuste problemaatilisust tuleb aga meenutada nii endale kui ka teistele.

Raamatus lükati ümber mitmeid, ka Eesti hariduses populaarseid väärarusaamu. Levinud on üleskutse õppida ainult probleeme lahendades, kaalumata selle plusse ja miinuseid. Raamatus näidatakse selgelt, et see pole parim tee mitte ainult teadmiste omandamiseks, vaid ka oskuste saavutamiseks ja nende rakendamiseks eri olukordades. Niisamuti tasub küsida, kas avastusõpe sobib ikka kõigile ja kui efektiivne see on. Seevastu kordamine ja harjutamine olid, on ja jäävad, kuigi tasub meeles pidada, et tõhus pole mitte mehaaniline kuhjuv kordamine, vaid korrata saab eri seostes ja viisidel. Tähtis on õpitava jõukohasus ja rakendatavus, sest just nende kaudu saab muuta õppimise mõtestatuks ja huvitavaks.

Ootamatu oli lugeda õppimist ja õpetamist käsitlevat raamatut, kus ei kirjutata motivatsioonist (kuigi mõnes kohas kasutati sõna motivatsioon ja sellega seotud mõisteid, nagu pingutamine) ega viidata ühelegi tänapäevasele vajaduste ja motivatsiooniteooriale. Samuti puuduvad raamatust viited kultuurile (kul- 
tuurierinevustele), keskkonnale (sotsiaalset keskkonda oli käsitletud pigem kui välist käitumist) ja individuaalsetele erinevustele. Nendeta ei saa aga olla teadust sellest, kuidas me õpime. Õnneks on eesti keelde tõlgitud mitmeid väljajäänud valdkondi käsitlevaid raamatuid. Jere Brophy „Kuidas õpilasi motiveerida“ (2016), Bill Rogersi „Käitumine klassiruumis. Tõhusa õpetamise, käitumisjuhtimise ja kolleegitoe käsiraamat“ (2012) ning „Taasleitud käitumine“ (2008) käsitlevad õpilaste vajadusi, motivatsiooni ja õpilaste motiveerimist. Kes tahavad end rohkem proovile panna ning komplekssemate arengu ja õppimise käsitlustega tutvuda, võiksid lugeda Aaro Toomela raamatuid „Kultuur, kõne ja Minu Ise“ (2016) ning „Minu Ise areng: inimlapsest Inimeseks“ (2017).

Kuna raamatus on toodud vastuolulisi leide, lisaks utreeritult ja intrigeerivalt, võib seda lugedes jõuda erinevatele järeldustele, olenevalt sellest, mis osa loetakse, missugused on lugeja eelteadmised, kas kasutatakse kiiret või aeglast mõtlemist jne. Kiire mõtlemine on mõnus, aga võib viia ka rappa. Aeglane mõtlemine on keeruline ja pingutustnõudev, kuid annab tervikpildi nendest tänapäevastest haridusalastest teadmistest, mida selles raamatus kirjeldatakse. Mina lugesin ja interpreteerisin raamatut enda teadmistest lähtudes. Olles psühholoogiataustaga, uurinud ja õpetanud hariduspsühholoogia vallas, olen kõnealuste teemade korral ilmselt mõnevõrra kompetentsem (suurem ekspert) kui paljud teised. Seega võis hinnangute andmist mõjutada ekspertide pimetähn (lk 13): ma ei püüdnud algajaid õpetada, küll aga püüdsin aru saada laiale lugejaskonnale mõeldud raamatust. See osutus vahel päris keeruliseks. Kuna igaüks loeb ja interpreteerib loetavat oma varasematele teadmistele-uskumustele tuginedes, peitub selles oht igaühele. Raamatu pealiskaudne ja pisteline lugemine võib viia seniste uskumuste (ka väärarusaamade) kinnistamiseni, isegi kui autorid püüdsid neid ümber lükata.

\section{Viidatud kirjandus}

Bergeron (2017). How to engage in pseudoscience with real data: A criticism of John Hattie's arguments in Visible Learning from the perspective of a statistician. McGill Journal of Education, 52(1). Retrieved from http://mje.mcgill.ca/article/view/9475/7229.

Brophy, J. (2016). Kuidas õpilasi motiveerida. Käsiraamat õpetajatele. Tallinn: Archimedes. Külastatud aadressil http://eduko.archimedes.ee/files/raamat_veebi.pdf.

Eacott, S. (2017). School leadership and the cult of the guru: The neo-taylorism of Hattie. School Leadership \& Management, 37(4), 413-426. https://doi.org/10.1080/13632434.2017.1327428

Kahneman, D. (2017). Kiire ja aeglane mõtlemine. Tallinn: Tänapäev. 
Kikas, E., Peets, K., \& Hodges, E. V. E. (2014). Collective student characteristics alter the effects of teaching practices on academic outcomes. Journal of Applied Developmental Psychology, 35(4), 273-283. https://doi.org/10.1016/j.appdev.2014.04.004

Pakarinen, E., \& Kikas, E. (2019). Child-centered and teacher-directed practices in relation to calculation and word problem solving skills. Learning and Individual Differences, 70, 76-85. https://doi.org/10.1016/j.lindif.2019.01.008

Peets, K., \& Kikas, E. (2017). Teachers' promotion or inhibition of children's aggression depends on peer-group characteristics. Journal of Clinical Child \& Adolescent Psychology, 46(6), 848-857. https://doi.org/10.1080/15374416.2015.1079778

Rogers, B. (2008). Taasleitud käitumine. Tartu: Tartu Ülikooli Kirjastus.

Rogers, B. (2012). Käitumine klassiruumis. Tõhusa õpetamise, käitumisjuhtimise ja kolleegitoe käsiraamat. Archimedes. Külastatud aadressil https://dspace.ut.ee/handle/10062/40599.

Rømer, T. A. (2019). A critique of John Hattie's theory of Visible Learning. Educational Philosophy and Theory, 51(6), 587-598. https://doi.org/10.1080/00131857.2018.1488216

Slavin, R. (2018). John Hattie is wrong. Retrieved from https://robertslavinsblog.wordpress.com/2018/06/21/john-hattie-is-wrong/.

Toomela, A. (2016). Kultuur, kõne ja Minu Ise. Tallinn: Eesti Keele Sihtasutus.

Toomela, A. (2017). Minu Ise areng: inimlapsest Inimeseks. Tartu: Väike Vanker.

Võgotski, L. (1978). Mind in society: The development of higher psychological processes. Cambridge: Harvard University Press. 